\title{
Factors affecting hedgehog (Erinaceus europaeus) attraction to rural villages in arable landscapes
}

\author{
Carly E. Pettett $^{1}$ (1) $\cdot$ Tom P. Moorhouse ${ }^{1} \cdot$ Paul J. Johnson $^{1} \cdot$ David W. Macdonald $^{1}$
}

Received: 23 August 2016 / Revised: 7 February 2017 / Accepted: 10 May 2017 /Published online: 25 May 2017

(C) The Author(s) 2017. This article is an open access publication

\begin{abstract}
Although residential areas are often unfavourable for wildlife, some species can take advantage of the available shelter and anthropogenic sources of food such as supplementary feeding. The European hedgehog (Erinaceus europaeus) is increasingly associated with gardens and villages and less so with arable farmland. Suggested drivers for this include the following: hedgehogs' attraction to higher food densities, including natural prey and anthropogenic sources, a greater range of day nest sites and warmer microclimates in rural villages, coupled with decreased risk of predation by badgers (Meles meles). We investigated the contribution of these drivers by radio-tracking hedgehogs on four arable sites, two with badgers present. Seventy-eight hedgehogs were tracked, 32 yielding enough data to calculate home range sizes. At the home range and landscape scales, gardens and buildings were the highest ranked habitats compared with their availability. Woodland and arable land were the lowest ranked compared with their availability. Villages were the most selected habitat for nesting. When hedgehogs were found closer to buildings, their ranges were smaller and we speculate this is due to increased food availability in villages. Where badgers were present hedgehogs remained closer to cover and their home ranges were on average 12.2 ha smaller. On badger-occupied sites, $50 \%$ fewer radio-tracking fixes were on arable land. We
\end{abstract}

Electronic supplementary material The online version of this article (doi:10.1007/s10344-017-1113-6) contains supplementary material, which is available to authorized users.

Carly E. Pettett

carly.pettett@gmail.com

1 Wildlife Conservation Research Unit, Department of Zoology, Recanati-Kaplan Centre, University of Oxford, Tubney House, Abingdon Road, Tubney, Oxfordshire OX13 5QL, UK conclude that resource availability coupled with nest site selection and badger presence drives hedgehogs' selection of rural villages. We found no effect of ambient temperature on habitat use. We recommend focusing conservation efforts on maintaining hedgehog populations in rural villages.

Keywords Arable farmland $\cdot$ Ranging behaviour $\cdot$ Foraging . Meles meles $\cdot$ Predation risk $\cdot$ Radio-tracking $\cdot$ Small mammal

\section{Introduction}

Built-up areas cover over $16,750 \mathrm{~km}^{2}$ of the UK and over $50 \%$ of the land in the UK is developed or used for agriculture (The UK National Ecosystem Assessment 2011). An increase in the size of built-up areas and intensively managed farmland has resulted in biodiversity losses in both urban and rural areas in the UK (Stoate et al. 2001; Foley et al. 2005; Macdonald and Feber 2015). Urbanisation may be particularly detrimental to wildlife, for example through habitat loss and fragmentation (Dickman 1987; Friesen et al. 1995; Lehtinen et al. 1999), road mortalities and the effect of roads as barriers to movement (Forman and Alexander 1998; Huijser and Bergers 2000; Rondinini and Doncaster 2002; Baker et al. 2004), human-wildlife conflict (Mosillo et al. 1999; Peine 2001; Gompper 2002; Hill et al. 2007; Delahay et al. 2009) and predation of native species by domestic pets (Baker et al. 2003; Woods et al. 2003).

There are also aspects of residential areas that are beneficial for wildlife, for example, low numbers of natural predators (Eden 1985; Gering and Blair 1999; Møller 2012), the availability of supplementary food (Doncaster et al. 1990; Fedriani et al. 2001; Prange et al. 2003; Fuller et al. 2008) and altered physical conditions, such as higher temperatures due to urban warming (Eden 1985; Pickett et al. 2001). There may also be 
higher occurrence of some natural prey species in urban areas allowing predator numbers to increase (e.g. Cooke et al. 2006). These advantageous qualities have allowed some species to thrive in residential areas, particularly omnivorous species, which can take advantage of human food waste (Fedriani et al. 2001; McKinney 2002; Chace and Walsh 2006).

Here, we focus on the Western European hedgehog (Erinaceus europaeus), a generalist predator of macroinvertebrates, which is increasingly becoming associated with the human environment, such as gardens and rural villages, and less so with agricultural land (Hubert et al. 2011; Yarnell et al. 2014; Van De Poel et al. 2015). In the UK, hedgehog numbers are declining, but with more severe declines in rural than urban areas (JNCC 2010; Aebischer et al. 2011; Roos et al. 2012). Even within rural areas, hedgehogs favour rural villages rather than open farmland and arable land is particularly under-selected (Hof and Bright 2010a; Hof et al. 2012). We examine the drivers of hedgehogs' increasing association with villages in rural areas, aiming to establish the causes of their population declines in agricultural areas - and in doing so highlight potential conservation measures.

Several factors might plausibly influence hedgehogs' attraction to rural villages over arable farmland. The hedgehog's diet mainly comprises macroinvertebrates (Yalden 1976; Wroot 1984). Hedgehog abundance is positively correlated with the earthworm abundance of grass fields, and habitats in rural villages such as amenity grassland and garden lawns sustain high numbers of earthworms compared with intensively managed arable fields (Doncaster 1994; Micol et al. 1994; Curry et al. 2002; Young et al. 2006). Hedgehogs also take advantage of waste and pet food left out by humans (Yalden 1976; Morris 1985; Hubert et al. 2011). The availability of nesting habitat may also attract hedgehogs to villages. Although hedgerows are frequently used for nesting in rural areas (Haigh et al. 2012), hedgehogs may also show a preference for nesting close to buildings (Rautio et al. 2014).

Rural villages may also act as refuges from predation (Hof et al. 2012). The European badger (Meles meles) is the main predator of hedgehogs in the UK. Badgers are thought to limit hedgehog numbers in rural areas (Hof and Bright 2010a) and hedgehog abundance on grass fields is negatively correlated with badger activity and sett density in the local area (Micol et al. 1994; Young et al. 2006). The mechanism for this relationship is unknown, it may be due to direct predation (Doncaster 1994; Hof and Bright 2010a; Trewby et al. 2014), avoidance of badgers (Hof et al. 2012; Pettett et al. 2017) or competition for food (Doncaster 1992). Badgers avoid building setts in residential areas (Neal and Cheeseman 1996) and therefore villages may act as refuge from badger predation (Doncaster 1994), although badgers can become quite abundant on the outskirts of urban areas (Davison et al. 2008). In residential areas, hedgehogs may face attack from domestic dogs (Doncaster 1994), yet badgers are the only predator thought to be proficient in uncurling a hedgehog from its defensive position (Neal 1986).

Warmer temperatures may also attract hedgehogs to villages as, for a small endotherm, energy expenditure is high at low ambient temperatures (Shkolnik and Schmidt-Nielsen 1976; Wroot 1984; Speakman 1997). Warmer temperatures may also result in higher availability of invertebrate prey for hedgehogs (Crawford-Sidebotham 1972; Edwards and Bohlen 1996; Honek 1997) and increased chances of survival during winter hibernation (Hubert et al. 2011). Villages may offer nest sites with stable temperatures for hibernation, such as in or under buildings (Lausen and Barclay 2006).

We investigate the contribution of four expected drivers of hedgehogs' attraction to rural villages by measuring hedgehog habitat use, home range size and distance to key habitat features on four predominately arable sites, under varying predation-threat and climatic conditions. We hypothesise that village habitats will be selected over arable farmland and that:

1. Hedgehogs that reside in villages, a habitat we speculate has a higher availability of prey and supplementary food (Doncaster 1994; Micol et al. 1994; Curry et al. 2002; Young et al. 2006; Hubert et al. 2011) than the surrounding arable land, will have smaller home ranges than those that utilise arable land.

2. Hedgehogs will show a preference for nesting close to buildings, and villages will have a greater variety of secure nesting habitats than on arable land (Rautio et al. 2014).

3. When badgers are present, hedgehogs will avoid arable land and therefore be found closer to buildings and cover (Doncaster 1994; Hof et al. 2012).

4. Due to the higher energetic costs associated with foraging at cold temperatures (Wroot 1984), when ambient temperatures are colder hedgehogs will be found closer to buildings and cover.

\section{Methods}

\section{Study sites}

Four sites were selected, two in North Norfolk (UK grid refs: TF 9606125469 and TG 16716 36586) and two in North Yorkshire (SE 9051181822 and SE 68646 24715) (Online Resource 1, Figs. A1-A4). Badgers were present on the farmland on one site in each county; presence was determined by surveys for tracks, active setts and active latrines in October 2013 and April 2014. Sightings by landowners and during radio-tracking studies also confirmed that badgers were active at these sites (Online Resource 1, Figs. A1-A4; Table A1). Sites were all at least $65 \%$ arable land, predominately cereal 
crops, with some pasture and rough grassland fields (Online Resource 1, Table A1). Rural villages were within $2.5 \mathrm{~km}$ of the farm and all contained amenity grassland including parks, playing fields and church yards. Villages were surrounded by small pasture fields and arable land.

\section{Hedgehog tracking}

Hedgehogs were captured using red spotlights and anaesthetised using isoflurane (Natural England Licence 2014/SCI/0298, HO PIL 30/10293). A small patch of spines on the rump was clipped and a $10 \mathrm{~g}$ radio-tag was glued to the clipped spines using epoxy resin. Hedgehogs were marked using six $1 \mathrm{~cm}$ long pieces of coloured heat-shrink tubing glued in a patch at the rear. Hedgehogs were then tracked on the sites from July to October 2013 and April-September 2014. Each site was visited for between four and eight nights at a time in turn over the season, with a mean of 41 nights (s.d. = 8) spent at each site. Whilst on site, hedgehogs were tracked between sunset and 4 am and a radio-tracking fix was obtained for each hedgehog in turn. Hedgehogs were tracked using a hand-held three element yagi directional antenna (Wildlife Materials International, Murphysboro, USA) and a TRX-1000S receiver (Wildlife Materials International, Murphysboro, USA). We recorded the GPS location of the hedgehog to the nearest $5 \mathrm{~m}$, the habitat it was found in (i.e. amenity grassland, arable land, buildings and gardens, hedgerow, pasture, rough grassland and woodland and scrub), and its distance from cover, (i.e. scrub, hedgerow or shrubs). The distance of the hedgehog at each tracking fix from hedgerows, buildings and badger activity was estimated using proximity analysis in ArcGIS (Esri, Redlands, CA, USA). Often hedgehogs were in enclosed gardens we did not have access to; in these cases triangulation was performed (Kenward 2000). To test whether hedgehogs avoided arable land in the study, the percentage of radio-tracking fixes on arable land was calculated for each hedgehog.

\section{Nesting}

Radio-tracking was also carried out before sunset on an ad hoc basis, with the aim of recording at least one nest site per hedgehog. The GPS location of the hedgehogs' day nests was recorded, along with the general and specific habitat the nest was found in. General habitat was categorised as follows: 'arable', 'pasture' and 'village' (including amenity grassland, gardens and buildings) and 'woodland' (see Haigh et al. 2012). The specific habitat within each of these general habitats was recorded as 'buildings', 'hedgerows', 'scrub' (including brambles and under bushes) and 'other'. To assess whether particular features of a hedgerow prompted hedgehog selection for day nesting, six hedgerows were randomly selected on each of the farms including two where hedgehogs had nested at some point during the 2013 and 2014 field seasons. Surveys of these hedgerows were carried out in June 2015 following the DEFRA hedgerow survey handbook methodology (DEFRA 2007).

\section{Temperature}

The hourly ambient temperature was recorded using ten data loggers per site during radio-tracking. To measure air temperature close to the ground, each was placed $30 \mathrm{~cm}$ off the ground. The loggers were covered with a foil dish in order to mitigate the effect of direct sunlight. Loggers were placed in a variety of habitats: two in the centre of arable fields, two in the hedgerow of arable fields, two outside farm buildings, two in gardens and two on amenity grassland. Logger placement was selected randomly in fields and gardens where access was granted and where they would encounter minimal interference, e.g. flower beds in gardens and under isolated trees in the centre of fields. For each radio-tracking fix, the mean ambient temperature from all of the loggers, at the time closet to when the fix was taken, was calculated.

\section{Statistical analysis}

To test for differences in home range size between hedgehogs that selected village habitats and those that selected arable habitats, on sites with and without badgers, home range estimates was calculated for each hedgehog over the two seasons, in the program Ranges (Anatrack Ltd., Dorset, UK). Estimates included $100 \%$ minimum convex polygons (MCP), which includes all tracking fixes and is frequently used as a home range measure in hedgehogs tracking studies (Riber 2006; Dowding et al. 2010a; Haigh et al. 2013) and, in order to estimate the core range of the hedgehog, 95 and 50\% kernel density estimates (Riber 2006). The predictor variables used were site, sex and mean distance to buildings during the two seasons (a measure of how much time a hedgehog spent in the village or close to human dwellings) and body mass.

The number of fixes obtained for each hedgehog varied between 1 and 53 fixes over the entire tracking period $($ mean $=17$; s.d. $=12)$. All tracking fixes were included in the analysis of distance to hedgerows, cover and buildings. For hedgehog home range analysis, accumulation curves were created and it was deemed that only hedgehogs with at least 20 fixes should be included, resulting in 32 hedgehogs in the analyses, with a mean of 29 fixes per hedgehog and a range of 20-53 fixes. For more in-depth analysis of hedgehog core home range, analysed by kernel estimates, only 21 hedgehogs with at least 25 positional fixes were deemed to have enough tracking fixes to be included.

Compositional analysis was performed to examine hedgehogs' habitat selection as this method is comparable to previous studies of hedgehog habitat use (Hof and Bright 2010a; 
Haigh et al. 2013). Two analyses were performed following Aebischer et al. (1993). Firstly, at the landscape scale to assess $100 \% \mathrm{MCP}$ home range selection within the wider landscape, and secondly, to assess the habitats used within a $100 \% \mathrm{MCP}$ home range compared with their availability in the home range. To examine habitat selection at the landscape scale, an area of $5 \mathrm{~km}^{2}$ around each site was digitised and categorised as 'amenity grassland', 'arable land', 'buildings', 'gardens', 'hedgerow', 'pasture' and 'rough grassland' and 'woodland and scrub'. To describe the habitats available at the home range scale, 'buildings' and 'gardens' were merged into one category as it was often difficult to distinguish the precise habitat of a hedgehog in an enclosed garden. Only one of the four study sites had any set-aside (1.4 ha) and therefore set-aside was not included in the analysis.

To examine differences in the proportion of radio-tracking fixes that hedgehogs were found on arable land on sites with and without badgers, a generalised linear model was constructed with the proportion of fixes that each hedgehog was found on arable land as the response variable and site and sex as the explanatory variables, with a binomial link and weighted by the number of tracking fixes for each hedgehog. Only hedgehogs with at least 10 tracking fixes, where calculating a percentage was deemed reasonable, were included in the analysis.

Compositional analysis was used to examine nest-site selection within the hedgehog's home range, measured by $100 \%$ MCP. Also, binomial logistic regression was used in order to assess whether the attributes of a hedgerow could predict whether or not it was used for hedgehog nesting during 2013 and 2014. Due to only six hedgerows being selected by hedgehogs for nesting, only a small number of attributes could be included in the analysis, these included the following: hedgerow height, hedgerow width and the height from the ground to the base canopy. The identity of the farm on which the hedgerow was located was included as a fixed blocking factor.

Linear mixed effects models were constructed using the $\mathrm{R}$ software (R Core Team 2014) to test whether hedgehogs' mean distance to buildings, distance to cover and distance to hedgerow varied between those sites - characterised as with or without badgers present, between males and females, and with the ambient temperature. Hedgehog ID was included as a random factor in each model. To analyse hedgehog distance from badger activity, including badger sightings latrines and setts, we generated a random number of spatial points on each badger-occupied site, equal to the number of actual radiotracking fixes. We then constructed a linear model to test for differences in the distance of the random points to badger activity with the distance of the actual tracking fixes to badger activity.

All results are stated as mean \pm standard error unless otherwise stated.

\section{Results}

\section{Summary}

A total of 46 hedgehogs were tracked in 2013 and 42 in 2014. Ten of the hedgehogs tracked in 2014 had also been captured in 2013, giving a total of 78 individuals, comprising $28 \mathrm{fe}-$ males and 50 males (see Online Resource 1, Table A2 for details of study subjects). We wished to capture 20 hedgehogs at each site, but twice as many hedgehogs were found on sites without badgers (site A: 24 and site B: 28), than on sites with badgers (site C: 14 and site D: 12). For the 78 hedgehogs, a total of 1324 GPS fixes was obtained. In the home range analyses, 32 hedgehogs were included (site A: 8 , site B: 12 , site C: 4 and site D: 8 ). Sixty-six day nest locations were recorded from 42 individuals. Eight hedgehogs died during the study; three from unknown causes, three road casualties, one electrocuted on electrified chicken wire and one possible badger predation.

\section{Habitat use}

Habitat use was statistically significantly non-random (Table 1). At both scales, gardens and buildings were the highest ranked habitats compared with their availability, on sites with and without badgers (Online Resource 1, Figs. A5-A8). Woodland was the least or second least selected habitat in all analyses and at all scales. Arable land was the next least selected habitat after woodland. Other habitats were interchangeably selected depending on the scale. Hedgerow was ranked highly when comparing the proportion available at the landscape scale with the proportion within the home range but became less selected when comparing the availability within home ranges with the proportion of tracking fixes in this habitat. Amenity grassland was ranked highly at the local scale but less so at the landscape scale.

There was a difference in habitat selection at the landscape scale on sites with and without badgers (Table 1). On sites with badgers, buildings were ranked first, and on sites with no badgers gardens and hedgerow were ranked above buildings. The mean proportion of buildings included in the hedgehogs' home ranges at the landscape scale was $3.16 \pm 0.71 \%$ on sites with no badgers, and $6.95 \pm 1.25 \%$ on sites with badgers. Additionally, on sites with no badgers, arable land was ranked higher than on sites with badgers and amenity grassland was ranked lower. There was no difference between hedgehog habitat selection at the local scale between sites with and without badgers and on sites where badgers were present. At the local scale on sites with no badgers, the mean percentage of fixes in buildings or gardens was $44.1 \pm 4.2 \%$ and on sites with badgers $38.1 \pm 3.4 \%$. However, on sites with badgers, habitat use was not significantly different from random, possibly due to low hedgehog numbers on these sites. 
Table 1 The ranking of habitats selected by radio-tracked hedgehogs when (a) comparing the habitats available at the landscape scale with those in a hedgehog's home range and (b) comparing the habitats hedgehogs were found during radio-tracking with the habitats available within the home range

\begin{tabular}{|c|c|c|c|c|c|c|c|c|c|}
\hline \multicolumn{10}{|c|}{$100 \% \mathrm{MCP}$ home range selection in the landscape } \\
\hline Rank & 6 & 5 & 4 & 3 & 2 & 1 & 0 & $p$ & $\lambda$ \\
\hline All & $\mathrm{GA} \gg \gg$ & $\stackrel{\mathrm{BD}}{>>}$ & $\stackrel{\mathrm{HR}}{>>}$ & $\begin{array}{c}\mathrm{PA} \\
>>- \\
>\end{array}$ & $\mathrm{AM}>$ & $\begin{array}{r}\mathrm{AB} \\
>\end{array}$ & WD & $0.002 * *$ & 0.29 \\
\hline Males & $\mathrm{GA} \gg \gg$ & $\stackrel{\mathrm{BD}}{>>}$ & $\stackrel{H R}{>>}$ & $\mathrm{PA}>$ & $\mathrm{AM}>$ & $\begin{array}{r}\text { WD } \\
>\end{array}$ & $\mathrm{AB}$ & $0.002 * *$ & 0.03 \\
\hline Females & GA $>$ & $\mathrm{BD}>$ & $\mathrm{HR}>$ & $\mathrm{PA}>$ & $\mathrm{AM}>$ & $\stackrel{\mathrm{AB}}{>}$ & WD & $0.004 * *$ & 0.11 \\
\hline Badgers & $\mathrm{BD}>$ & $\mathrm{GA}>$ & $\mathrm{HR}>$ & $\mathrm{GA}>$ & $\underset{>>}{\mathrm{AM}}$ & $\stackrel{\mathrm{AB}}{>}$ & WD & $0.002 * *$ & 0.10 \\
\hline $\begin{array}{l}\text { No } \\
\text { bad- } \\
\text { gers }\end{array}$ & $\mathrm{GA} \gg \gg$ & $\mathrm{BD}>$ & $\stackrel{\mathrm{HR}}{\gg>}$ & $\mathrm{PA}>$ & $\mathrm{AB}>$ & $\begin{array}{r}\text { WD } \\
>\end{array}$ & $\mathrm{AM}$ & $0.002 * *$ & 0.09 \\
\hline \multicolumn{10}{|c|}{ Habitat selection within $100 \% \mathrm{MCP}$ home range } \\
\hline Rank & 5 & 4 & 3 & 2 & 1 & 0 & $p$ & $\lambda$ & \\
\hline All & $\mathrm{BD} \& \mathrm{GA}>$ & $\mathrm{AM}>$ & $\mathrm{PA}>$ & $\mathrm{HR}>$ & $\underset{>>}{\mathrm{AB}}$ & WD & $0.004^{* *}$ & 0.39 & \\
\hline Males & $\underset{\gg>}{\mathrm{BD} \& \mathrm{GA}}$ & $\stackrel{\mathrm{PA}}{>>}$ & $\mathrm{AB}>$ & $\mathrm{AM}>$ & $\stackrel{H R}{>>}$ & WD & $0.024 *$ & 0.26 & \\
\hline Females & $\mathrm{BD} \& \mathrm{GA}>$ & $\mathrm{AM}>$ & $\mathrm{PA}>$ & $\mathrm{HR}>$ & $\mathrm{AB}>$ & WD & 0.14 & 0.30 & \\
\hline Badgers & $\underset{>\gg}{\mathrm{BD}} \& \mathrm{GA}$ & $\mathrm{PA}>$ & $\mathrm{AM}=$ & $\mathrm{AB}=$ & $\mathrm{WD}=$ & HR & 0.18 & 0.25 & \\
\hline $\begin{array}{l}\text { No } \\
\text { bad- } \\
\text { gers }\end{array}$ & $\mathrm{BD} \& \mathrm{GA}>$ & $\mathrm{AM}>$ & $\mathrm{HR}>$ & $\mathrm{PA}>$ & $\stackrel{\mathrm{AB}}{>>}$ & WD & 0.06 & 0.32 & \\
\hline
\end{tabular}

Habitats are ranked from most selected to least from left to right. $>>>$ indicates a statistically significant difference in hedgehog preference between habitat groups. $>$ indicates a non-significant difference and $=$ indicates no difference. Analysis includes 32 hedgehogs with at least 20 radio-tracking fixes. Ranking was carried out following (Aebischer et al. 1993)

$A B$ arable, $A M$ amenity grass, $B D$ buildings, $G A$ gardens, $H R$ hedgerow, $P A$ pasture, $W D$ woodland
At the landscape scale, males and females selected very similar habitats compared with their availability (Table 1). However, the least selected habitat for females was woodland and for males was arable land. At the local scale, for females amenity grassland was ranked higher than for males and for males arable land was ranked higher than for females.

The percentage of hedgehog tracking fixes recorded on arable land varied with site (ANOVA, $X^{2}=49.3, p<0.0001$, $3 d f$, Fig. 1). On sites where badgers were present, a lower percentage of tracking fixes was recorded on arable land: $13.7 \pm 5.1 \%$ compared with $27.3 \pm 3.8 \%$, on sites without badgers. There was no evidence that the percentage of fixes recorded on arable land differed between males and females (ANOVA, $X^{2}=0.26, p=0.61,1 d f$ ).

\section{Home range size}

All home range size estimates increased with distance from buildings (Table 2, Fig. 2, Online Resource 1; Figs. A9-12). Home range size also varied between sites and this was statistically significant when home range was measured by $100 \%$ MCP (Table 2, Fig. 3). Where badgers were present, hedgehogs had smaller home ranges when measured by $100 \%$ MCP (Table 2, Fig. 3). On sites with badgers, hedgehogs had a mean home range of $9.7 \pm 1.9$ ha compared with a home

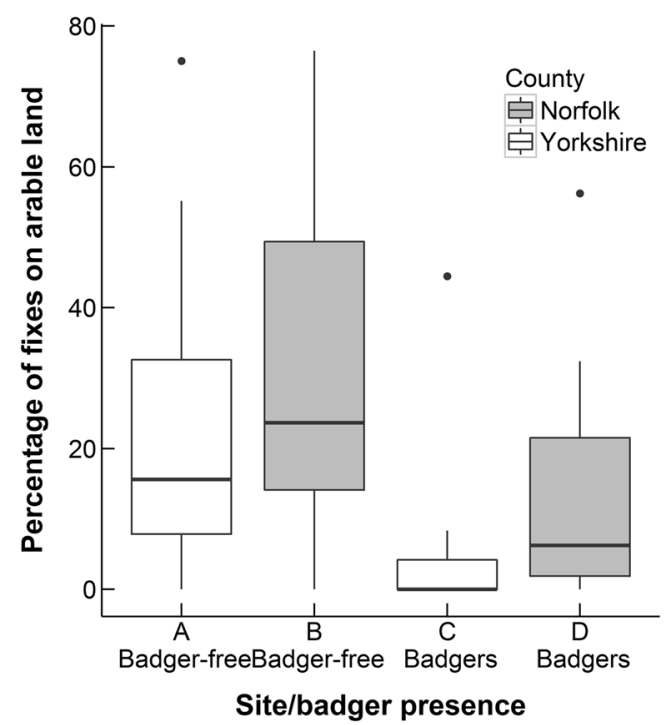

Fig. 1 The significant difference between sites with and without badgers in the percentage of radio-tracking fixes that a hedgehog was found on arable land, in radio-tracking studies carried out on four sites in Norfolk and Yorkshire in July-October 2013 and April-September 2014 
Table 2 The results of three linear models to test the differences in hedgehog home range size on sites with and without badgers, between males and females and with the mean distance a hedgehog was found from buildings. Home range was calculated by minimum convex polygons (MCP) with $100 \%$ of radio-tracking fixes and by 95 and $50 \%$ kernel estimates

\begin{tabular}{lllllll}
\hline Response & Variable & $d f$ & $F$ statistic & $p$ value & Effect size & $95 \%$ CI \\
\hline $100 \%$ MCP & Site B NO BADGERS & 3,25 & 5.75 & $0.004^{* *}$ & -0.427 & $-0.968,0.114$ \\
& C BADGERS & & & & -0.452 & $-1.228,0.324$ \\
& D BADGERS & & & & -0.735 & $-1.316,-0.154^{\mathrm{a}}$ \\
& Distance to buildings & 1,25 & 31.58 & $<0.0001^{* * *}$ & 0.028 & $0.018,0.038^{\mathrm{a}}$ \\
& Sex MALE & 1,25 & 12.20 & $0.002^{* *}$ & 0.699 & $0.287,1.110^{\mathrm{a}}$ \\
& Body mass & 1,25 & 0.072 & 0.791 & -0.000 & $-0.002,0.001$ \\
95\% Kernel & Site B NO BADGERS & 3,14 & 2.662 & 0.088. & -0.608 & $-1.338,0.122$ \\
& C BADGERS & & & & -0.308 & $-1.647,1.032$ \\
& $\quad$ D BADGERS & & & & -0.126 & $-0.871,0.619$ \\
& Distance to buildings & 1,14 & 20.228 & $0.0005^{* * *}$ & 0.030 & $0.016,0.044^{\mathrm{a}}$ \\
& Sex MALE & 1,14 & 1.800 & 0.201 & 0.360 & $-0.210,0.931$ \\
& Body mass & 1,14 & 0.391 & 0.542 & -0.001 & $-0.004,0.002$ \\
& Site B NO BADGERS & 3,14 & 2.999 & 0.067. & -0.539 & $-1.205,0.127$ \\
& C BADGERS & & & & -0.150 & $-1.372,1.071$ \\
& D BADGERS & & & & -0.141 & $-0.820,0.538$ \\
& Distance to buildings & 1,14 & 23.732 & $0.0002^{* * * *}$ & 0.029 & $0.017,0.042^{\mathrm{a}}$ \\
& Sex MALE & 1,14 & 2.589 & 0.130 & 0.391 & $-0.129,0.911$ \\
& Body mass & 1,14 & 0.034 & 0.857 & -0.000 & $-0.003,0.002$ \\
\hline
\end{tabular}

Distance to building is the mean distance each hedgehog was found to the nearest building during two seasons of radio-tracking in 2013 and 2014. Words in italics following categorical variables indicate the reference category. Ranges were $\log$ transformed before analysis. Site A and female are the reference categories

***Significant at $p<0.001$ level; **Significant at $p<0.01$ level; *significant at $p<0.05$.near significance

${ }^{a}$ Ninety-five percent confidence interval of the effect size does not contain zero range of $21.9 \pm 5$ ha at sites without badgers. However as Fig. 3 shows, the site differences in home range size cannot be attributed to badger presence alone; there were also differences between the two sites with

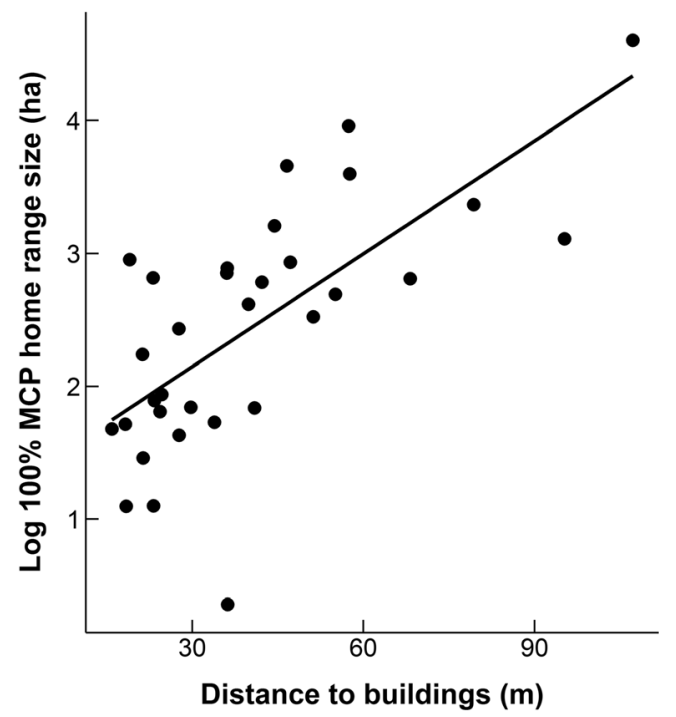

Fig. 2 The significant relationship between the mean distance a hedgehog was found from buildings during radio-tracking and a hedgehog's home range size measured by $100 \%$ minimum convex polygons (MCP) on four sites in Norfolk and Yorkshire in JulyOctober 2013 and April-September 2014 badgers present and the two sites with badgers absent. Males had consistently larger home ranges than females: using $100 \%$ MCP, males had a mean range of $21.6 \pm 5.8$ ha compared with a female range of

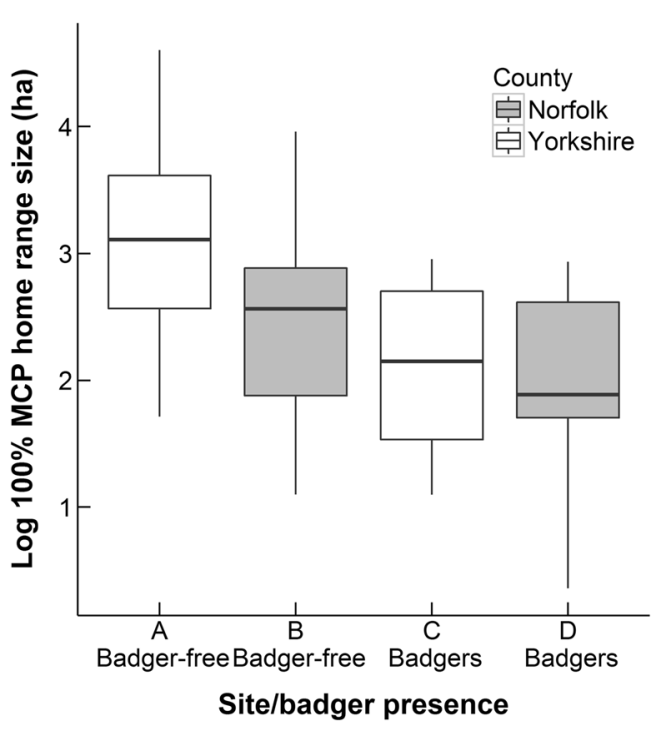

Fig. 3 The significant effect of site, characterised by badger presence, on a hedgehog's home range size measured by $100 \%$ minimum convex polygons (MCP) on four sites in Norfolk and Yorkshire in JulyOctober 2013 and April-September 2014 
$12.4 \pm 2.7$ ha (Table 2). We found no effect of body mass on home range size (Table 2).

\section{Nesting}

The general habitat used for nesting was non-random ( $\lambda=0.37, p=0.002)$. Habitats used were ranked as follows: village $>>>$ woodland $>$ pasture $>$ arable, where $>>>$ indicates a significant difference between habitats. Although the mean percentage of village habitat in the hedgehog home ranges was $35.35 \pm 3.41 \%, 60 \%$ of the 66 nests studied were within villages. Forty-eight percent of these were constructed in scrub, $25 \%$ in buildings (e.g. under garden sheds or in hay barns) and 23\% in hedgerows. Nests in hedgerows in villages were in the hedgerows of amenity grassland or garden hedgerows. Across the four villages, $28 \%$ of hedgerows were predominately conifer species, $19 \%$ privet (Ligustrum sp.) and 19\% hawthorn (Crataegus monogyna). Only eight nests were constructed in arable fields and eight in pasture fields. When farmland was used, hedgerows were by far the most chosen habitat, $75 \%$ of nests, and were predominately hawthorn (C. monogyna) and blackthorn (Prunus spinosa) with brambles (Rubus fruticosus). Day nest sites were frequently observed to be situated towards the centre of home ranges (Online Resource 1, Fig. A13).

The mean total width of the hedgerow was wider in farmland hedgerows in which hedgehogs nested than hedgerows hedgehogs were not observed nesting in, but this was only near significance in a logistic regression (Fig. 4, $z=7.13, p=0.08$ ). For nests made with natural materials, $67 \%$ contained leaf litter, 56\% dry grass and $50 \%$ were in brambles. Three hedgehogs used holes in both living and dead trees. A variety of manmade structures were used for nesting in villages including garden sheds, hay barns, compost heaps and under tarpaulin.

\section{Distance to habitat features}

On the two sites where badgers were present, hedgehogs were found a mean distance of $4.7 \pm 1.1 \mathrm{~m}$ closer to cover, $13 \pm 1.7 \mathrm{~m}$ closer to hedgerows and $7.2 \pm 3.5 \mathrm{~m}$ closer to buildings (Fig. 5, Table 3), than on the sites without badgers, although the analysis of distance to buildings was not statistically significant. When ambient temperature was lower, hedgehogs were found further from cover (Table 3). There was no evidence for a difference in the distance found to any of these features between males and females (Table 3).

We found a significant difference between the distance randomly generated tracking fixes were from badger activity and the distance that actual tracking fixes were found from badger activity $\left(t_{1,246}=36.6, p<0.0001\right)$. The actual fixes were found

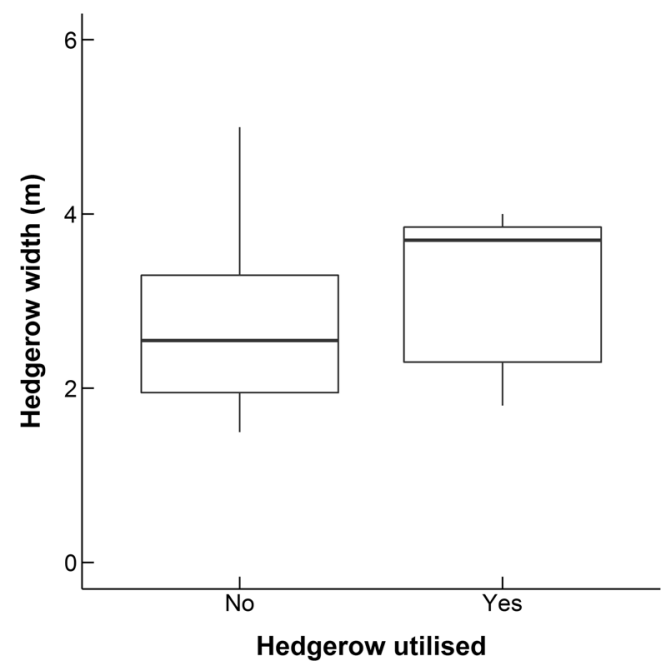

Fig. 4 The width of hedgerows selected or not by nesting hedgehogs on four sites in Norfolk and Yorkshire. Hedgerow width was near statistical significance in determining whether hedgehogs nested in a hedgerow or not (logistic regression, $z=7.13, p=0.08$ )

a mean of $728 \pm 16 \mathrm{~m}$ to badger activity compared with $473 \pm 23 \mathrm{~m}$ for the randomly generated points (Online Resource 1, Figs. A14 and A15).

\section{Discussion}

Our aim was to examine the contribution of four expected drivers of hedgehogs' selection of rural villages in arable landscapes. Firstly, we confirmed that hedgehogs selected rural villages over the surrounding predominantly arable farmland. Buildings and gardens were most the selected habitat

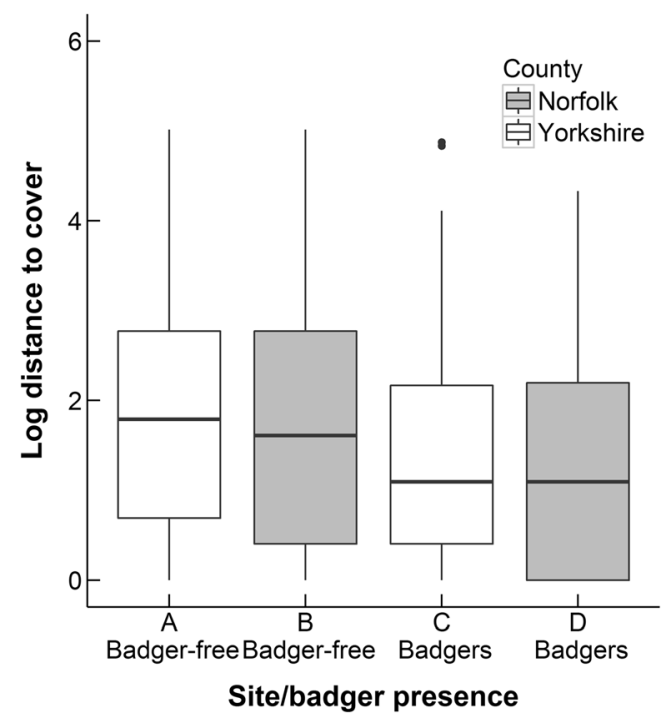

Fig. 5 The significant difference between sites with and without badgers in the distance hedgehogs were found to cover, including hedgerows, scrub and shrubs, during radio-tracking studies carried out on four sites in Norfolk and Yorkshire in July-October 2013 and April-September 2014 
Table 3 The results of three linear models to test the differences in the distance a hedgehog was found to hedgerow, cover and buildings on sites with and without badgers, between males and females and with ambient temperature

\begin{tabular}{|c|c|c|c|c|c|c|}
\hline Response & Variable & $d f$ & $\begin{array}{l}F \\
\text { statistic }\end{array}$ & $p$ value & $\begin{array}{l}\text { Effect } \\
\text { size }\end{array}$ & $95 \% \mathrm{CI}$ \\
\hline \multirow[t]{5}{*}{$\begin{array}{l}\text { Distance to } \\
\text { hedgerow }\end{array}$} & $\begin{array}{l}\text { Site B } \\
\quad \text { BADGER-FREE }\end{array}$ & 3,55 & 3.088 & $0.034 *$ & 0.443 & $-0.290,1.195$ \\
\hline & C BADGERS & & & & -0.025 & $-1.006,0.975$ \\
\hline & D BADGERS & & & & -0.860 & $-1.725,0.007$ \\
\hline & Ambient temperature & $\begin{array}{l}1, \\
9- \\
14\end{array}$ & 0.180 & 0.672 & -0.011 & $-0.061,0.039$ \\
\hline & Sex $M A L E$ & 1,50 & 0.196 & 0.660 & 0.137 & $-0.475,0.760$ \\
\hline \multirow[t]{5}{*}{ Distance to cover } & $\begin{array}{l}\text { Site B } \\
\text { BADGER-FREE }\end{array}$ & 3,53 & 3.428 & $0.023 *$ & -0.216 & $-0.562,0.127$ \\
\hline & C BADGERS & & & & -0.652 & $\begin{array}{l}-1.122 \\
-0.191^{\mathrm{a}}\end{array}$ \\
\hline & D BADGERS & & & & -0.462 & $\begin{array}{l}-0.864, \\
-0.064^{\mathrm{a}}\end{array}$ \\
\hline & Ambient temperature & $\begin{array}{l}1, \\
8- \\
86\end{array}$ & 7.908 & $0.005^{* *}$ & -0.039 & $\begin{array}{l}-0.066 \\
\quad-0.012^{\mathrm{a}}\end{array}$ \\
\hline & Sex $M A L E$ & 1,48 & 0.804 & 0.374 & 0.128 & $-0.155,0.414$ \\
\hline \multirow[t]{5}{*}{ Distance to building } & $\begin{array}{l}\text { Site B } \\
\quad \text { BADGER-FREE }\end{array}$ & 3,59 & 2.536 & 0.065 & 0.246 & $-0.207,0.702$ \\
\hline & C BADGERS & & & & -0.508 & $-1.104,0.098$ \\
\hline & D BADGERS & & & & -0.199 & $-0.738,0.332$ \\
\hline & Ambient temperature & $\begin{array}{l}1, \\
9- \\
04\end{array}$ & 0.757 & 0.384 & -0.012 & $-0.039,0.015$ \\
\hline & Sex $M A L E$ & 1,55 & 1.498 & 0.226 & 0.233 & $-0.144,0.616$ \\
\hline
\end{tabular}

Words in italics following categorical variables indicate the reference category. The reference site, site A, was badger-free

***Significant at $p<0.001$ level; **significant at $p<0.01$ level; *significant at $p<0.05$.near significance

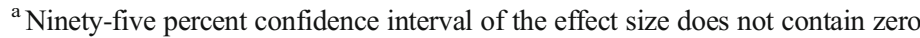

compared with their availability at the landscape and local scale, and arable land, along with woodland, was underselected compared to its availability.

Hedgerow was ranked highly when comparing the proportion available at the landscape scale with the proportion within the home range but became less selected when comparing the availability within home ranges with the proportion of tracking fixes in this habitat, unlike in previous studies (Hof and Bright 2010b). It may be that hedgerows are only heavily used when hedgehogs are on arable land, as cover from predation (Hof et al. 2012), whereas in this study, as hedgehogs spent much of their time in the village, there was other cover available, e.g. shrubs, scrub and out-houses. Alternatively, in this study, hedgerows may have been selected for nesting rather than foraging and thus hedgehogs selected home ranges with high availability of hedgerow but did not utilise the centre of hedgerows during nightly tracking (mean percentage of area that was hedgerow at the landscape scale on the four sites: $1.83 \pm 0.05 \%$, mean percentage of hedgerow at the home range scale: $3.36 \pm 0.22 \%$ ). It is also worth noting that the type of hedgerow available in rural villages differs from that on open arable land; there was a range of hedgerow types such as conifer and privet whereas on arable land hedgerows were predominately hawthorn and blackthorn.

Amenity grassland was ranked highly at the local scale compared with its availability in the home range, but less so at the landscape scale. Hedgehogs were frequently observed foraging on football pitches, playparks and cricket pitches in the villages. On one site (site C), the most frequently used foraging habitat was a mowed grass strip in the centre of an arable field used for flying model aircraft. These findings indicate that amenity grassland is a valuable foraging habitat for hedgehogs and could explain why hedgehogs select villages. Hedgehogs were also frequently located at food left out specifically for hedgehogs or for pets, indicating that supplementary food availability is also important in determining hedgehog habitat use (Hubert et al. 2011; Pettett 2016).

At the local scale, for females amenity, grassland was ranked higher than for males and for males arable land was ranked higher than for females. Females tend to be more 
sedentary than males and focus on foraging and raising young, whereas the strategy of male hedgehogs is to move around trying to locate females to mate with (Reeve 1994). This idea explains why females selected amenity grassland to a higher degree compared to its availability as this appears to be a key foraging habitat for hedgehogs. This is supported by the larger home range sizes of males. Also, males were observed to cross arable land more frequently, e.g. to move between villages.

The first of our four hypotheses asserted that hedgehogs residing in villages would have smaller home ranges than those that selected arable land. We found a positive correlation between the mean distance a hedgehog was found from buildings and home range size, regardless of the method used to calculate the home range size. We speculate that this finding may be due to a lower availability of resources, i.e. lower earthworm abundance, on arable land than on mowed grass habitats in rural villages (Doncaster 1992; Doncaster 1994; Doncaster et al. 2001), and the availability of supplementary food, which might require hedgehogs to forage further on arable land. Increased locomotion may be energetically costly (Kenagy and Hoyt 1989; Covell et al. 1996) and this could be a driver of hedgehogs' preference of villages (Pettett et al. 2017). However, further study of prey availability in rural villages compared with arable land is needed to substantiate this. Home range size may also be negatively correlated to the density of a population (Wolff 1985; Trewhella et al. 1988; Moorhouse and Macdonald 2008). In this study, the sites where hedgehogs had the largest home ranges (sites A and B) had the highest densities of hedgehogs. It could be that hedgehogs in villages with higher numbers of hedgehogs spill out onto the surrounding arable land in search of food.

This study also provides support for our second hypothesis; that hedgehogs prefer to build day nests in villages rather than on arable land. Village habitats were ranked as the most selected habitat for nesting. Within village habitats, scrub was the most used habitat. In this study, scrub included bushes and areas of brambles and weeds, which were plentiful in gardens. Nest sites in villages were often inaccessible such as under garden sheds, which provides evidence that nest sites may be more secure in villages, although human disturbance of nests in villages is potentially problematic. These results indicate that nest site choice may be a factor in determining hedgehogs' selection of rural villages. However, we did not measure nest site availability in this study and so it is not clear whether hedgehogs nested in villages due to the variety and structure of available nest sites or whether they were simply nesting close to good foraging habitat. Nest sites tended to be reasonably central within the home range (Online Resource 1, Fig. A13) and therefore it is likely that food availability plays a part in their selection. However, it could be argued that hedgehogs simply forage close to good nesting sites.

Hedgerows were still selected for nesting in villages and were the most common habitat used for nesting on farmland, as in a study by Haigh et al. (2012b) in Ireland, where $82 \%$ of 16 nests on farmland were found in hedgerows. There was a relationship between increasing hedgerow width and increasing likelihood of hedgehogs nesting in it, but this relationship was not statistically significant, possibly because the number of hedgerows utilised on arable farmland was low compared with those not utilised ( 20 not used, 8 used). The UK Biodiversity Action Plan hedgerow target states that the minimum width for a favourable hedgerow for biodiversity should be $1.5 \mathrm{~m}$ (DEFRA 2007). The mean width of hedgerows used for day nests in this study was $3.18 \pm$ SE $0.33 \mathrm{~m}$ compared with $2.78 \pm$ SE 0.25 for those unused, giving some indication that hedgehogs may require a width greater than that currently deemed as favourable, although a larger study is needed to investigate this further.

The third of our four hypotheses asserted that when badgers are present hedgehogs will avoid arable land and therefore be found closer to buildings and cover. This study demonstrated that on sites with badgers, hedgehogs stayed closer to buildings and had a lower percentage of radio-tracking fixes on arable land than hedgehogs on sites without badgers. Hedgehogs have previously been shown to stay closer to cover in the presence of badgers on four further sites in England by Hof et al. (2012) and studies of other small mammals also show a trade-off between prey availability and distance to cover in the presence of predators (Lima and Dill 1990; Kotler et al. 1991; Hughes and Ward 1993; Orrock 2004). We can conclude that hedgehogs may perceive a greater threat from badger presence further from cover, on sites where badgers are present.

Hedgehogs on sites with badgers had smaller home ranges (when calculated by $100 \% \mathrm{MCP}$ ) than hedgehogs on sites without badgers, regardless of the number of radio-tracking fixes they were observed to be on arable land, suggesting that hedgehogs have restricted movement when badgers are present, even in village habitats. Furthermore, on the two badgeroccupied sites, buildings were ranked before gardens and hedgerows at the landscape scale and vice versa when badgers were absent. Finally, the hedgehogs tracked in this study were found further from badger activity than a randomly generated set of tracking fixes. These results support the notion that predator avoidance is one possible cause of hedgehogs' selection of rural villages (Micol et al. 1994; Laundre et al. 2010; Hof et al. 2012). However, badger presence was not the only cause of the site differences in home range size, there were differences between the two sites with badgers and the two sites without, plausibly due to other differences between the sites such as resource availability. Additionally, on sites without badgers, buildings and gardens were still the most selected habitat.

There were no confirmed predation events by badgers during this study as in previous studies of hedgehogs on arable land (Hof and Bright 2010a). Therefore research into the 
mechanism behind the effect of the negative relationship between badgers and hedgehogs is needed, such as following badger and hedgehog movements at the same time to assess the frequency of predation events and how often hedgehogs and badgers come into contact. Resource availability will play a key role in this relationship. For example, hedgehogs on site D did move away from the village to forage on the grassy model plane airstrip even though this was closer to badger activity. Road deaths were the highest cause of mortality in the study and could potentially impact on rural hedgehog populations (Wembridge et al. 2016).

We found no evidence for our final hypothesis; that hedgehogs may be attracted to the warmer microclimate in rural villages than on the surrounding farmland. Hedgehogs were in fact found further from cover when it was colder. The reason for this finding is unclear; it may be a result of hedgehogs travelling further from cover to find macroinvertebrates, which are scarce in colder weather (Crawford-Sidebotham 1972; Edwards and Bohlen 1996; Honek 1997). We found no evidence that the relationship was due to hedgehogs utilising the centre of arable fields after harvesting when temperatures are colder. We also tested for an effect of time in the evening - as temperatures are warmer earlier on in the evening when hedgehogs may be closer to edge habitats because they have just emerged from the nest- but found no effect. Future study should include the effect of humidity and rainfall on ranging behaviour.

\section{Summary}

Our evidence indicates that hedgehogs preferentially select rural villages rather than open farmland, particularly arable land. We speculate that the availability of natural and supplementary prey may be one reason hedgehogs are attracted to rural villages. This is supported by the finding that hedgehogs that spent more time closer to buildings had smaller home range sizes. Further research into prey availability in rural landscapes is needed to establish the contribution of food availability to hedgehog distribution. Our study of nest sites confirms that hedgehogs prefer to build day nests in villages than on the surrounding arable farmland. We also found some evidence that badger presence alters hedgehog habitat use, increasing their association with buildings and cover, suggesting that badgers may be another potential cause of hedgehogs' preference for rural villages. However, on sites with no badgers, hedgehogs also selected buildings and gardens over any other habitat type.

Our research confirms the importance of rural villages in sustaining hedgehog numbers in the UK countryside. Our findings suggest a two-pronged approach for hedgehog conservation: firstly, maintaining hedgehog subpopulations in rural villages, for example by improving garden management and preserving green spaces and secondly, improving the surrounding arable land, chiefly in respect to cover from predation and connectivity between rural villages. Although this research shows that residential areas are selected by hedgehogs, hedgehogs are also in decline in urban areas (PTES and BHPS 2015) and villages and face a suite of problems which were beyond the scope of this study including the following: poisoning from molluscicides and rodenticides (Keymer et al. 1991; Dowding et al. 2010b), a lack of habitat connectivity due to enclosed gardens (Hof and Bright 2009) and deaths on roads (Huijser and Bergers 2000; Rondinini and Doncaster 2002). Wildlife friendly gardening and the consideration of habitat connectivity in urban planning may reduce some of these threats to hedgehogs (Hof and Bright 2009). On arable land, increasing hedgerow length and quality will offer cover from badger predation (Hof et al. 2012; this study), and provide nest sites (Haigh et al. 2012) and dispersal corridors between rural villages (Moorhouse et al. 2014). These recommendations are relevant to many species struggling to survive in landscapes dominated by human habitation and intensively managed farmland, for example small mammals (Fitzgibbon 1997; Kotzageorgis and Mason 1997; Baker and Harris 2007; Gelling et al. 2007), birds (Green et al. 1994; MacDonald and Johnson 1995; Cornulier et al. 2011) and amphibians and reptiles (Ficetola and De Bernardi 2004; Salazar et al. 2016).

Acknowledgements This research was funded by a grant from the People's Trust for Endangered Species and the British Hedgehog Preservation Society. We thank the farmers who allowed us access to their land over the course of the study. We also thank those who assisted with data collection in the field, particularly Sarah Thresher and Monica Griffith.

Open Access This article is distributed under the terms of the Creative Commons Attribution 4.0 International License (http:// creativecommons.org/licenses/by/4.0/), which permits unrestricted use, distribution, and reproduction in any medium, provided you give appropriate credit to the original author(s) and the source, provide a link to the Creative Commons license, and indicate if changes were made.

\section{References}

Aebischer NJ, Davey PD, Kingdon NG (2011) National Gamebag Census: Mammal Trends to 2009. http://www.gwct.org.uk/ ngcmammals.

Aebischer NJ, Robertson PA, Kenward RE (1993) Compositional analysis of habitat use from animal radio-tracking. Ecology 74:13131325

Baker PJ, Ansell R, Dodds P et al (2003) Factors affecting the distribution of small mammals in an urban area. Mamm Rev 33:95-100. doi:10. 1046/j.1365-2907.2003.00003.x

Baker PJ, Harris S (2007) Urban mammals: what does the future hold? An analysis of the factors affecting patterns of use of residential gardens in Great Britain. Mamm Rev 37:297-315. doi:10.1111/j. 1365-2907.2007.00102.x

Baker PJ, Harris S, Robertson CPJ et al (2004) Is it possible to monitor mammal population changes from counts of road traffic casualties? An analysis using Bristol's red foxes Vulpes vulpes as an example. Mamm Rev 34:115-130. doi:10.1046/j.0305-1838.2003.00024.x 
Chace JF, Walsh JJ (2006) Urban effects on native avifauna: a review. Landsc Urban Plan 74:46-69. doi:10.1016/j. landurbplan.2004.08.007

Cooke R, Wallis R, Hogan F et al (2006) The diet of powerful owls (Ninox strenua) and prey availability in a continuum of habitats from disturbed urban fringe to protected forest environments in southeastern Australia. Wildl Res 33:199-206

Cornulier T, Robinson RA, Elston D et al (2011) Bayesian reconstitution of environmental change from disparate historical records: hedgerow loss and farmland bird declines. Methods Ecol Evol 2:86-94

Covell DF, Miller DS, Karasov WH (1996) Cost of locomotion and daily energy expenditure by free-living swift foxes (Vulpes velox): a seasonal comparison. Can J Zool 74:283-290. doi:10.1139/z96-035

Crawford-Sidebotham TJ (1972) The influence of weather upon the activity of slugs. Oecologia 9:141-154. doi:10.2307/4214745

Curry JP, Byrne D, Schmidt O (2002) Intensive cultivation can drastically reduce earthworm populations in arable land. Eur J Soil Biol 38: 127-130. doi:10.1016/S1164-5563(02)01132-9

Davison J, Huck M, Delahay RJ, Roper TJ (2008) Urban badger setts: characteristics, patterns of use and management implications. J Zool 275:190-200. doi:10.1111/j.1469-7998.2008.00424.x

DEFRA (2007) Hedgerow survey handbook. A standard procedure for local surveys in the UK. Department for Environment, Food and Rural Affairs, London

Delahay RJ, Davison J, Poole DW et al (2009) Managing conflict between humans and wildlife: trends in licensed operations to resolve problems with badgers Meles meles in England. Mamm Rev 39:5366. doi:10.1111/j.1365-2907.2008.00135.x

Dickman CR (1987) Habitat fragmentation and vertebrate species richness in an urban environment. J Appl Ecol 24:337-351. doi:10. 2307/2403879

Doncaster ACP, Dickman CR, Macdonald DW et al (1990) Feeding ecology of red foxes (Vulpes vulpes) in the City of Oxford, England. J Mammal 71:188-194

Doncaster C, Rondinini C, Johnson PCD (2001) Field test for environmental correlates of dispersal in hedgehogs Erinaceus europaeus. J Anim Ecol 70:33-46. doi:10.1046/j.1365-2656.2001.00471.x

Doncaster CP (1994) Factors regulating local variations in abundance: field tests on hedgehogs, Erinaceus europaeus. Oikos 69:182-192. doi: $10.2307 / 3546136$

Doncaster CP (1992) Testing the role of intraguild predation in regulating hedgehog populations. Proc R Soc B Biol Sci 249:113-117. doi:10. 1098/rspb.1992.0092

Dowding CV, Harris S, Poulton S, Baker PJ (2010a) Nocturnal ranging behaviour of urban hedgehogs, Erinaceus europaeus, in relation to risk and reward. Anim Behav 80:13-21. doi:10.1016/j.anbehav. 2010.04.007

Dowding CV, Shore RF, Worgan A et al (2010b) Accumulation of anticoagulant rodenticides in a non-target insectivore, the European hedgehog (Erinaceus europaeus). Environ Pollut 158:161-166

Eden SF (1985) The comparative breeding biology of magpies Pica pica in an urban and a rural habitat (Aves: Corvidae). J Zool 205:325-334

Edwards CA, Bohlen PJ (1996) Biology and ecology of earthworms. Springer, New York

Fedriani JM, Fuller TK, Sauvajot RM (2001) Does availability of anthropogenic food enhance densities of omnivorous mammals? An example with coyotes in southern California. Ecography (Cop) 24: 325-331

Ficetola GF, De Bernardi F (2004) Amphibians in a human-dominated landscape: the community structure is related to habitat features and isolation. Biol Conserv 119:219-230

Fitzgibbon CD (1997) Small mammals in farm woodlands: the effects of habitat, isolation and surrounding land-use patterns. J Appl Ecol 34: 530-539. doi: $10.2307 / 2404895$
Foley JA, Defries R, Asner GP, et al (2005) Global consequences of land use. Science (80- ) 309:570-574. doi: 10.1126/science.1111772

Forman RTT, Alexander LE (1998) Roads and their major ecological effects. Annu Rev Ecol Syst 29:207-231. doi:10.1146/annurev. ecolsys.29.1.207

Friesen LE, Eagles PF, Mackay RJ (1995) Effects of residential development on forest-dwelling neotropical migrant songbirds. Conserv Biol 9:1408-1414. doi:10.1046/j.1523-1739.1995.09061408.x

Fuller RA, Warren PH, Armsworth PR et al (2008) Garden bird feeding predicts the structure of urban avian assemblages. Divers Distrib 14: 131-137

Gelling M, Macdonald DW, Mathews F (2007) Are hedgerows the route to increased farmland small mammal density? Use of hedgerows in British pastoral habitats. Landsc Ecol 22:1019-1032. doi:10.1007/ s10980-007-9088-4

Gering JC, Blair RB (1999) Predation on artificial bird nests along an urban gradient: predatory risk or relaxation in urban environments? Ecography (Cop) 22:532-541. doi:10.1111/j.1600-0587.1999. tb01283.x

Gompper ME (2002) Top carnivores in the suburbs? Ecological and conservation issues raised by colonization of North-eastern North America by coyotes. Bioscience 52:185-190

Green RE, Osborne PE, Sears EJ (1994) The distribution of passerine birds in hedgerows during the breeding season in relation to characteristics of the hedgerow and adjacent farmland. J Appl Ecol:677-692

Haigh A, O'Riordan RM, Butler F (2012) Nesting behaviour and seasonal body mass changes in a rural Irish population of the Western hedgehog (Erinaceus europaeus). Acta Theriol (Warsz) 57:321331. doi:10.1007/s13364-012-0080-2

Haigh A, O'Riordan RM, Butler F (2013) Habitat selection, philopatry and spatial segregation in rural Irish hedgehogs (Erinaceus europaeus). Mammalia 77:163-172. doi:10.1515/ mammalia-2012-0094

Hill NJ, Carbery KA, Deane EM (2007) Human-possum conflict in urban Sydney, Australia: public perceptions and implications for species management. Hum Dimens Wildl 12:101-113

Hof AR, Bright PW (2010a) The value of agri-environment schemes for macro-invertebrate feeders: hedgehogs on arable farms in Britain. Anim Conserv 13:467-473. doi:10.1111/j.1469-1795.2010.00359.x

Hof AR, Bright PW (2010b) The impact of grassy field margins on macro-invertebrate abundance in adjacent arable fields. Agric Ecosyst Environ 139:280-283. doi:10.1016/j.agee.2010.08.014

Hof AR, Bright PW (2009) The value of green-spaces in built-up areas for western hedgehogs. Lutra 52:69-82

Hof AR, Snellenberg J, Bright PW (2012) Food or fear? Predation risk mediates edge refuging in an insectivorous mammal. Anim Behav 83:1099-1106. doi:10.1016/j.anbehav.2012.01.042

Honek A (1997) The effect of temperature on the activity of Carabidae (Coleoptera) in a fallow field. Eur J Entomol 94:97-104

Hubert P, Julliard R, Biagianti S, Poulle ML (2011) Ecological factors driving the higher hedgehog (Erinaceus europeaus) density in an urban area compared to the adjacent rural area. Landsc Urban Plan 103:34 43. doi:10.1016/j.landurbplan.2011.05.010

Hughes JJ, Ward D (1993) Predation risk and distance to cover affect foraging behaviour in Namib Desert gerbils. Anim Behav 46: 1243-1245. doi:10.1006/anbe.1993.1320

Huijser MP, Bergers PJM (2000) The effect of roads and traffic on hedgehog (Erinaceus europaeus) populations. Biol Conserv 95:6-9

JNCC (2010) UK priority species pages - hedgehog (Erinaceus europaeus). Joint Nature Conservation Committee, Peterborough

Kenagy AGJ, Hoyt DF (1989) Speed and time-energy budget for locomotion in golden-mantled ground squirrels. Cal State J Med 7:150

Kenward RE (2000) A manual for wildlife radio tagging. Academic Press, London 
Keymer IF, Gibson EA, Reynolds DJ (1991) Zoonoses and other findings in hedgehogs (Erinaceus europaeus): a survey of mortality and review of the literature. Vet Rec 128:245-249

Kotler BP, Brown JS, Hasson O, Dec N (1991) Factors affecting gerbil foraging behavior and rates of owl predation. Ecology 72:2249 2260. doi: $10.2307 / 1941575$

Kotzageorgis GC, Mason CF (1997) Small mammal populations in relation to hedgerow structure in an arable landscape. J Zool 242:425434. doi:10.1111/j.1469-7998.1997.tb03846.x

Laundre JW, Hernandez L, Ripple WJ (2010) The landscape of fear: ecological implications of being afraid. Open Ecol J 3:1-7. doi:10. 2174/1874213001003030001

Lausen CL, Barclay RMR (2006) Benefits of living in a building: big brown bats (Eptesicus fuscus) in rocks versus buildings. J Mammal $87: 362-370$

Lehtinen RM, Galatowitsch SM, Tester JR (1999) Consequences of habitat loss and fragmentation for wetland amphibian assemblages. Wetlands 19:1-12. doi:10.1007/BF03161728

Lima SL, Dill LM (1990) Behavioral decisions made under the risk of predation: a review and prospectus. Can J Zool 68:619-640

Macdonald DW, Feber RE (2015) Wildlife conservation on farmland volume 1: managing for nature in lowland farms. Oxford University Press, Oxford

MacDonald DW, Johnson PJ (1995) The relationship between bird distribution and the botanical and structural characteristics of hedges. J Appl Ecol:492-505

McKinney ML (2002) Urbanization, biodiversity, and conservation. Bioscience 52:883-890

Micol T, Doncaster CP, Mackinlay LA (1994) Correlates of local variation in the abundance of hedgehogs Erinaceus europaeus. J Anim Ecol 63:851-860. doi:10.2307/5262

Møller AP (2012) Urban areas as refuges from predators and flight distance of prey. Behav Ecol 23:1030-1035

Moorhouse TP, Macdonald DW (2008) What limits male range sizes at different population densities? Evidence from three populations of water voles. J Zool 274:395-402. doi:10.1111/j.1469-7998.2007.00399.x

Moorhouse TP, Palmer SCF, Travis JMJ, Macdonald DW (2014) Hugging the hedges: might agri-environment manipulations affect landscape permeability for hedgehogs? Biol Conserv 176:109-116. doi:10.1016/j.biocon.2014.05.015

Morris PA (1985) The effects of supplementary feeding on movements of hedgehogs (Erinaceus europaeus). Mamm Rev 15:23-33. doi:10. 1111/j.1365-2907.1985.tb00383.x

Mosillo M, Heske EJ, Thompson JD (1999) Survival and movements of translocated raccoons in northcentral Illinois. J Wildl Manag 63: 278-286. doi: $10.2307 / 3802510$

Neal E (1986) The natural history of badgers. Croom Helm Ltd, London

Neal E, Cheeseman C (1996) Badgers. Poyser, London

Orrock JL (2004) Rodent foraging is affected by indirect, but not by direct, cues of predation risk. Behav Ecol 15:433-437. doi:10. 1093/beheco/arh031

Peine JD (2001) Nuisance bears in communities: strategies to reduce conflict. Hum Dimens Wildl 6:223-237. doi:10.1080/ 108712001753461301

Pettett CE (2016) Factors affecting hedgehog distribution and habitat selection in rural landscapes. $\mathrm{PhD}$ Thesis. University of Oxford

Pettett CE, Johnson PJ, Moorhouse TP et al (2017) Daily energy expenditure in the face of predation: hedgehog energetics in rural landscapes. J Exp Biol 220:460 LP-468

Pickett STA, Cadenasso ML, Grove JM, Nilon CH, Pouyat RV, Zipperer WC, Costanza R (2001) Urban ecological systems: linking terrestrial ecological, physical, and socioeconomic components of metropolitan areas. Annu Rev Ecol Syst 32(1):127-157

Prange S, Gehrt SD, Wiggers EP (2003) Demographic factors contributing to high raccoon densities in urban landscapes. J Wildl Manage 324-333
PTES and BHPS (2015) The state of Britain's hedgehogs 2015

R Core Team (2014) R: a language and environment for statistical computing. R Foundation for Statistical Computing, Vienna

Rautio A, Valtonen A, Auttila M, Kunnasranta M (2014) Nesting patterns of European hedgehogs (Erinaceus europaeus) under northern conditions. Acta Theriol (Warsz) 59:173-181. doi:10.1007/s13364013-0150-0

Reeve N (1994) Hedgehogs. Poyser, London

Riber AB (2006) Habitat use and behaviour of European hedgehog Erinaceus europaeus in a Danish rural area. Acta Theriol (Warsz) 51:363-371

Rondinini C, Doncaster CP (2002) Roads as barriers to movement for hedgehogs. Funct Ecol 16:504-509. doi:10.1046/j.1365-2435.2002. 00651.x

Roos S, Johnston A, Noble D (2012) UK hedgehog datasets and their potential for long-term monitoring. The British Trust for Ornithology, Norfolk

Salazar RD, Montgomery RA, Thresher SE, Macdonald DW (2016) Mapping the relative probability of common toad occurrence in terrestrial lowland farm habitat in the United Kingdom. PLoS One 11:e 0148269

Shkolnik A, Schmidt-Nielsen K (1976) Temperature regulation in hedgehogs from temperate and desert environments. Physiol Zool 49:56-64

Speakman J (1997) Factors influencing the daily energy expenditure of small mammals. Proc Nutr Soc 56:1119-1136. doi:10.1079/ PNS19970115

Stoate C, Boatman ND, Borralho RJ et al (2001) Ecological impacts of arable intensification in Europe. J Environ Manag 63:337-365. doi: 10.1006/jema.2001.0473

The UK National Ecosystem Assessment (2011) The UK National Ecosystem Assessment: synthesis of the key findings. UNEPWCMC, Cambridge

Trewby ID, Young R, McDonald RA et al (2014) Impacts of removing badgers on localised counts of hedgehogs. PLoS One 9:2-5. doi:10. 1371/journal.pone.0095477

Trewhella WJ, Harris S, McAllister FE (1988) Dispersal distance, homerange size and population density in the red fox (Vulpes vulpes): a quantitative analysis. J Appl Ecol 25:423-434. doi:10.2307/ 2403834

Van De Poel JL, Dekker J, Van Langevelde F (2015) Dutch hedgehogs Erinaceus europaeus are nowadays mainly found in urban areas, possibly due to the negative effects of badgers Meles meles. Wildlife Biol 21:51-55. doi:10.2981/wlb.00072

Wembridge DE, Newman MR, Bright PW, Morris PA (2016) An estimate of the annual number of hedgehog (Erinaceus europaeus) road casualties in Great Britain. Mammal Comms 2:8-14

Wolff JO (1985) The effects of density, food, and interspecific interference on home range size in Peromyscus leucopus and Peromyscus maniculatus. Can J Zool 63:2657-2662

Woods M, McDonald R, Harris S (2003) Predation of wildlife by domestic cats Felis catus in Great Britain. Mamm Rev 33:174-188. doi:10. 1046/j.1365-2907.2003.00017.x

Wroot AJ (1984) Feeding ecology of the European hedgehog. PhD Thesis. Royal Holloway College, University of London

Yalden DW (1976) The food of the hedgehog in England. Acta Theriol (Warsz) 21:401-424

Yarnell RW (2014) Using occupancy analysis to validate the use of footprint tunnels as a method for monitoring the hedgehog Erinaceus europaeus. Mamm Rev 44:234-238. doi:10.1111/mam.12026

Young RP, Davison J, Trewby ID et al (2006) Abundance of hedgehogs (Erinaceus europaeus) in relation to the density and distribution of badgers (Meles meles). J Zool 269:349-356. doi:10.1111/j.14697998.2006.00078.x 